\title{
AS REGRAS DO JOGO: Organização das Nações Unidas e Relações Centro-Periferia
}

THE RULES OF THE GAME: United Nations and Center-Periphery Relations

Juliana Pinto Lemos da Silva ${ }^{1}$

\begin{abstract}
RESUMO
Este trabalho busca introduzir a investigação dos debates acerca da reforma da ONU e do Conselho de Segurança, à luz da investigação sobre as dinâmicas entre centro e periferia dentro da instituição. Os resultados mostram que as relações assimétricas entre países do centro e da periferia, que estão presentes no sistema internacional, também ocorrem no âmbito das Nações Unidas.
\end{abstract}

Palavras-chave: ONU; Relações Centro-Periferia; Assimetria

\begin{abstract}
This paper seeks to introduc the debates about the UN and the Security Council reforms through the analysis of the dynamics between center and periphery in the United Nations. The results show that the assymetric relations between the center and the periphery that happen in the international system also occur inside the United Nations and directly influence the reform proposals.
\end{abstract}

Keywords: UN; Relations Center-Periphery; Assymetry

\section{INTROUÇÃo}

A ordem internacional contemporânea passa por mudanças estruturais e ganha contornos mais multipolares. Tais mudanças têm origem nas crises financeiras, no desenvolvimento de novas tecnologias, no surgimento de novos temas na agenda internacional, e na ascensão de países que desejam maior participação nos espaços multilaterais de tomada de decisão. Nesta conjuntura propensa a transformações, antigas reivindicações a favor de uma reforma geral das Nações Unidas e do seu Conselho de Segurança ganham novo fôlego, sendo tema recorrente no discurso daqueles que defendem uma ordem internacional mais democrática e correspondente à realidade internacional atual.

Este trabalho busca fazer uma introdução à investigação dos debates acerca da

1 Bacharela em Ciência Política pela Universidade Federal do Estado do Rio de Janeiro (UNIRIO), Rio de Janeiro, Brasil. 
reforma geral da Organização das Nações Unidas. Através da análise das dinâmicas entre países do centro e os da periferia dentro do arcabouço organizacional das Nações Unidas, e com foco nas relações assimétricas no Conselho de Segurança, serão expostas as condições que propiciaram o aumento das críticas sobre a falta de representatividade do órgão e a defesa de uma reforma geral da instituição.

Primeiramente, será feito um levantamento das principais regras estabelecidas pela Carta das Nações para o funcionamento da organização. Em seguida, a importância das dinâmicas das relações entre o centro e a periferia para a investigação das assimetrias presentes na instituição será exposta. Por fim, será feito um levantamento dos argumentos daqueles que pleiteiam uma reforma tanto das Nações Unidas, quanto do seu Conselho de Segurança. O objetivo é expor as assimetrias presentes não apenas no Conselho de Segurança, mas em toda a instituição, que revelam que as relações de dominação do centro sobre a periferia que ocorrem no sistema internacional também existem no âmbito das Nações Unidas, uma instituição que se fundamentou em princípios considerados democráticos, mas que na prática demonstra exercer pouco esta veia.

\section{A Organização das Nações Unidas e o Conselho de Segurança}

Após o fim da Segunda Guerra Mundial, o sentimento geral era de que o mundo precisava de uma paz global, relativamente estabilizada. Depois de debates sobre como alcançar a manutenção do recentemente conquistado estado de paz, teve origem o que a comunidade internacional confiava que seria, a partir dali o principal meio de articulação multilateral a respeito de questões de segurança internacional e gerenciamento da paz: a Organização das Nações Unidas (ONU).

Em outubro de 1945, 51 países colaboraram para a formulação do documento fundamental da instituição, a Carta das Nações Unidas. No primeiro artigo, os objetivos fundamentais da instituição são apontados, entre eles, a conservação da paz e da segurança internacional, e a cooperação internacional para "resolver os problemas internacionais de caráter econômico, social, cultural ou humanitário". No segundo artigo, estão estabelecidos princípios como os da igualdade dos Estados, da resolução pacífica de conflitos e do 
respeito à soberania. ${ }^{2}$

É fundamental para este trabalho a exposição da estrutura organizacional da ONU, que engloba a definição dos elementos que compõem sua estrutura e o papel e relevância de cada um dos atores. Quando tal estrutura é analisada, torna-se possível observar algumas de suas assimetrias, sejam entre Assembleia Geral e o Conselho de Segurança, ou no interior do Conselho.

O Conselho de Segurança, um dos principais órgãos da instituição, é responsável pela gerência da paz e da segurança internacional, e suas resoluções devem ser acatadas por todos os membros das Nações Unidas. De fato, o Conselho surge como uma tentativa de "ordenar as relações internacionais a partir de um diretório de grandes potências" (VARGAS, 2011: p.20), porque entende que, para que haja uma gerência da paz a nível global, é preciso que os atores influentes entrem em um acordo sobre princípios a serem seguidos.

Inicialmente, o Conselho era formado por cinco membros permanentes (República da China, Estados Unidos, França, Reino Unido e União Soviética), e seis membros não permanentes. Os países que ocupam cadeiras não permanentes têm poderes limitados e mandatos temporários, de modo que a posição que ocupam não se equipara a dos permanentes. Posteriormente, a República da China foi substituída pela República Popular da China, enquanto a Rússia assumiu as responsabilidades da União Soviética na ONU após a Guerra Fria. Durante seus 70 anos, a estrutura do Conselho praticamente não se alterou, passou apenas por uma reforma que ampliou o número de membros não-permanentes, em 1965. Naquele ano foi feita uma emenda na Carta das Nações aumentando a quantidade de cadeiras não permanentes de seis para dez, resultando num total de 15 membros para o Conselho de Segurança, e assim tem sido sua composição desde então (VARGAS, 2011).

O processo de tomada de decisão no âmbito do Conselho é feito por votação, e exige a aprovação unânime dos membros permanentes, e não um consenso. 0 mais importante privilégio dos permanentes é o poder de vetar qualquer proposta. Isso significa que, para que uma resolução seja validada, é necessário que ao menos nove dos quinze países que fazem parte do órgão a aprovem, entre eles, todos os permanentes. Mesmo que todos os

2 Carta das Nações Unidas, Disponível em <http://www.planalto.gov.br/ccivil 03/decreto/19301949/d19841.htm>. Acesso em setembro de 2015. 
não permanentes votem a favor da decisão, e quatro fixos também concordem, se um permanente for contra, ele é capaz de vetar sozinho a proposta 3 .

Outra relevante atribuição do Conselho de Segurança é o gerenciamento das operações de manutenção da paz. Esse tipo de operação não está explicitamente descrito na Carta das Nações Unidas, mas já em 1948 as tropas multilaterais da ONU foram enviadas para o Oriente Médio com o objetivo de supervisionar a suspensão dos conflitos entre países árabes e Israel, em guerra pela questão palestina. A operação foi a United Nations Truce Supervision Organization (Untso), o precedente que abriu caminhos para que outras missões de manutenção da paz pudessem ser colocadas em execução. Desde 1948 a ONU deu início a 78 operações, das quais 16 ainda estão em atividade (incluindo a Untso $)^{4}$

Hoje a ONU é uma das mais relevantes instituições do sistema internacional, um espaço multilateral onde se propõe debates sobre diversos problemas globais, sendo o Conselho de Segurança o seu órgão mais influente. O Conselho reforça as concepções de quem são os principais atores internacionais, e seu modo de funcionamento expõe que as relações presentes no seu interior se dão de forma desigual, refletindo os problemas de assimetria que são observados no sistema internacional atual.

\section{Assimetrias na ONU e no Conselho de Segurança}

Esta análise expôs, com base nas regras estabelecidas pela Carta das Nações para o regimento da $\mathrm{ONU}$, que a instituição deve prezar pelas relações democráticas entre seus membros. No entanto, o objetivo principal desta investigação é desconstruir tal ideia ao discutir as assimetrias presentes na organização à luz do debate sobre as relações entre representantes do centro e da periferia dentro do arcabouço das Nações Unidas. Para tanto, assimetrias entre o Conselho de Segurança e a Assembleia Geral serão analisadas, assim

3 Mais sobre a votação no Conselho de Segurança nos Capítulos V e VI da Carta das Nações, disponível em < http://www.planalto.gov.br/ccivil 03/decreto/1930-1949/d19841.htm>. Acesso em novembro de 2015.

$4 \quad$ ONU, 2015. Mais em $<$ http://www.un.org/en/peacekeeping/resources/statistics/factsheet.shtml $>$. Acesso em setembro de 2015. 
como desigualdades dentro do Conselho.

A primeira assimetria a ser exposta é a entre a Assembleia Geral e o Conselho de Segurança. A Assembleia é o fórum mais representativo do sistema internacional, e o Conselho é um diretório seleto de grandes potências (VARGAS, 2011). Algumas das regras adotadas pela ONU podem colaborar para que o Conselho sobressaia dentro do modelo institucional, e se institua uma relação assimétrica entre ele e outras divisões da organização. Um exemplo é que uma das principais regras da carta fundamental da instituição estabelece que nenhuma outra divisão, inclusive a Assembleia Geral, tem autoridade para examinar qualquer tema que já esteja sob a competência do Conselho. 0 artigo 12 da Carta diz:

Enquanto o Conselho de Segurança estiver exercendo, em relação a qualquer controvérsia ou situação, as funções que lhe são atribuídas na presente Carta, a Assembleia Geral não fará nenhuma recomendação a respeito dessa controvérsia ou situação, a menos que o Conselho de Segurança a solicite. (CARTA DAS NAÇÕES UNIDAS, artigo 12).

A regra dimensiona o quanto o órgão tem autoridade perante todo o sistema internacional, e como os seus participantes são importantes para as relações internacionais, especialmente os permanentes. A questão é que, enquanto a Assembleia Geral mostra-se a mais plural e representativa coalizão da política mundial, os membros permanentes do Conselho de Segurança representam apenas 2,59\% do total de Estados $^{5}$. 0 Conselho peca não apenas pela sua falta de representatividade, mas também pelo seu caráter não democrático, por não dar poder de decisão para países periféricos, ou os incluir no debate de forma igual, de modo a reproduzir as relações de dominação do centro sobre a periferia.

De fato, o lugar que o Conselho de Segurança ocupa na ONU e as funções exclusivas destinadas aos membros permanentes são um exemplo de como as relações entre os países dentro das Nações Unidas não são igualitárias. Vargas (2011) explica as consequências de tal assimetria, para a ONU e toda a comunidade internacional, ao afirmar que “(...) o Conselho de Segurança não exerce poder - exerce autoridade,

$5 \quad$ MILANI et al. Atlas da Política Externa Brasileira. Rio de Janeiro, EDUerj, 2014, p.108. 
legitimando ações de poder que de outra maneira teriam um custo político muito mais elevado" (VARGAS, 2011: p.36). As potências utilizam os instrumentos de uma instituição internacional que tem por pressuposto a democracia, para reforçar papéis de centro e periferia na ordem internacional. 0 valor que o Conselho tem no sistema e a influência dos permanentes fazem com que uma resolução tomada pelo órgão seja mais influente do que um apelo à responsabilidade internacional feito por um país não participante, e até mais poderoso do que demandas coletivas da Assembleia Geral.

A segunda assimetria ocorre dentro do próprio Conselho. Uma das principais questões que levanta debates sobre o órgão é a de que não existe uma equação de funções entre seus membros, e de fato, a Carta das Nações Unidas estabelece, por exemplo, o direito do veto para os membros permanentes, mas não para os membros nãopermanentes (CARTA DAS NAÇÕES UNIDAS, artigo 27.3), e também afirma que emendas ou modificações na Carta dependem da ratificação de dois terços dos membros das Nações Unidas, desde que inclua também a aprovação de todos os membros permanentes do Conselho (CARTA DAS NAÇÕES UNIDAS, artigo 108 e 109.2).

Este é mais um sinal de que as Nações Unidas não dão a atenção adequada às desproporcionalidades. Na divisão de encargos entre membros permanentes e não permanentes, nas tomadas de decisão e na formulação de resoluções, os participantes do Conselho de Segurança não vivem em uma situação igualitária de posições. Vargas (2011: p.93) sustenta que membros permanentes "dispõem de uma memória institucional do Conselho muito mais abrangente", além da vantagem de "terem desenvolvido (...) o hábito de trabalharem constantemente em conjunto". Apesar dessa questão, mesmo entre permanentes não existe uma relação de total horizontalidade. Para tanto, basta analisar algumas das ações unilaterais dos EUA ao longo da história, como a invasão do Iraque em 2003, que se deu sem o aval da ONU e reflete a falta de acatamento do país para com as decisões do Conselho.

Para além dessa questão, existe também o debate sobre o veto, que é a demonstração mais direta de que as potências detêm um poder de decisão efetivo sem precedentes, em contraposição aos países da periferia, que se encontram em desvantagem. 0 veto exercido apenas pelos permanentes é a prova de que o Conselho ajuda a reforçar assimetrias entre centro e periferia dentro das Nações Unidas. Vargas (2011) dá um exemplo ao destacar que vetos podem dar-se de formas diferentes. Por 
exemplo, quando diretos, pelo menos um dos permanentes se opõe à resolução proposta. O mecanismo também já foi usado para bloquear propostas que divergiam dos interesses das potências ou para evitar afrontas. Portanto, o veto é persistentemente usado para servir primeiro, aos interesses dos permanentes.

Existe também, segundo o autor, uma forma indireta de vetar uma resolução, que começa pelo desencorajamento do debate sobre uma questão que possa vir a causar impasses, ou interpelar manobras das potências permanentes. Esta prática é realizada quando um ou mais membros fixos querem adiar a discussão de um problema internacional, ou quando o mesmo não é prioridade aos olhos de tais países, o que leva à inércia do órgão diante de questões relevantes para a comunidade internacional. Herz (1999a) sugere uma solução para o veto indireto: o estabelecimento de mecanismos que obriguem o Conselho a discutir problemas a partir de critérios mais objetivos (como o número de refugiados ou mortos), o que pode limitar os interesses particulares dos países e originar uma ação mais rápida, baseada na verdadeira natureza do problema.

A terceira assimetria diz respeito às missões de paz da ONU. As operações mostraram ser um meio que o Conselho encontrou de legitimar intervenções e repartir as despesas, ou seja, os permanentes se viram com um grande discurso em mãos: o de que as intervenções não seriam ações das grandes potências, mas sim esforços de toda a comunidade internacional em defesa da paz e dos direitos humanos, com a vantagem de que os países dividiriam os custos de intervenções que sairiam muito caras (financeira e politicamente) para um país arcar sozinho.(SCHOEMAN, 2012).

Embora as decisões sobre a criação, manutenção ou expansão de uma operação sejam tomadas pelo Conselho de Segurança, o financiamento e as contribuições militares são responsabilidades coletivas de todos os membros das Nações Unidas. Diante disso, uma questão fundamental para entender as relações entre centro e periferia no âmbito da ONU emerge. Schoeman (2012, p.94) indica que durante a implementação das primeiras operações de paz foi sendo criada uma divisão internacional do trabalho que "via as principais potências e as superpotências assumindo a responsabilidade de financiar estas operações, ao passo que as médias e menores potências ofereciam as tropas". Os dados da Tabela 1 mostram os cinco países que mais contribuem militarmente para as operações de paz na atualidade, de acordo com o número total de militares ativos. 
Tabela 1 - Ranking do Total de Contribuições Militares para Operações de Paz (Julho 2015)

\begin{tabular}{|l|l|}
\hline Países & Total de militares em operações \\
\hline Bangladesh & 9398 \\
\hline Etiópia & 8309 \\
\hline Índia & 7960 \\
\hline Paquistão & 7665 \\
\hline Ruanda & 5600 \\
\hline Fonte: UN, Julho de 2015. Disponível em <http://www.un.org/en/peacekeeping/contributors/2015/jul15_2.pdf>.
\end{tabular}

Ao analisar a tabela percebe-se que os países no ranking são periféricos, apenas a Índia ocupa uma posição semiperiférica e intermediária. 0 primeiro membro permanente do Conselho a aparecer é a China, em $8^{\circ}$ lugar (3078 militares). 0 segundo é a França, em 32 (906 militares), seguido de Reino Unido (52 lugar, 287 militares), Estados Unidos (76º lugar, 78 militares) e Rússia (77º lugar, 76 militares).

A Tabela 2 mostra os cinco maiores contribuintes financeiros segundo as cotas para o rateio das despesas das operações, de acordo com a porcentagem de participação aprovada para cada país. A determinação das taxas é feita com base na escala de contribuições usada pela Assembleia Geral, e as taxas são as aprovadas para o período que vai de 2013 a 2015.

Tabela 2 - Ranking do Total de Contribuições Financeiras para Operações de Paz

\begin{tabular}{|l|l|}
\hline Países & Cota (em \%) \\
\hline Estados Unidos & 28,38 \\
\hline Japão & 10.83 \\
\hline França & 7.22 \\
\hline Alemanha & 7.14 \\
\hline Reino Unido & 6.68 \\
\hline
\end{tabular}

Fonte: UN, 2015. Disponível em <http://www.un.org/en/ga/search/view_doc.asp?symbol=A/67/224/Add.1> 
Os dados da Tabela 2 mostram que os países que mais contribuem financeiramente para as operações são grandes potências. Dos cinco primeiros, três são membros permanentes do Conselho (Estados Unidos, França e Reino Unido), e dois são candidatos a assentos fixos em caso de reforma (Alemanha e Japão). Os números oficiais da ONU comprovam a permanência do modelo de divisão do trabalho exposto por Schoeman (2012), com os maiores contribuintes financeiros das operações de paz atualmente sendo grandes potências centrais, enquanto as contribuições militares são lideradas por periferias e semiperiferias. 0 modelo prova, mais uma vez, que dentro das Nações Unidas as funções distintas do centro e das zonas periféricas refletem a condição assimétrica do sistema, onde o "trabalho braçal" é sempre feito pelos países da periferia.

A conclusão é que no Conselho de Segurança “(...) trabalhos são sempre condicionados pelo interesse e o comprometimento dos seus integrantes, particularmente dos membros permanentes. Sem vontade política e coincidência de posições, o Conselho é incapaz de atuar" (VARGAS, 2011: p. 44). Deste modo, pode-se entender que o Conselho é usado pelos permanentes para, entre outros objetivos, reforçar o papel dependente da periferia, e não para um bem coletivo. A solução diagnosticada afirma que é preciso fazer uma reforma geral nas Nações Unidas e, especialmente, no seu Conselho de Segurança. Mas como estimular uma reforma profunda em um órgão que depende da vontade política dos países que ocupam os assentos permanentes para tomar qualquer decisão?

\section{A reforma da $\mathrm{ONU}$}

Com o surgimento de novos elementos e novas ameaças no contexto internacional, e de novos fenômenos que fazem parte das relações internacionais contemporâneas, o debate sobre reformar as estruturas desgastadas da ONU e do Conselho de Segurança emerge mais uma vez. Herz (1999a) afirma que as propostas de reforma geral incluem aspectos que dizem respeito à democratização do caráter decisório dentro da instituição, abarcando questões sobre o equilíbrio de poder entre a Assembleia Geral e o Conselho de Segurança, a necessidade de ampliar o Conselho e reavaliar o veto, e sobre o estabelecimento de critérios mais claros sobre a jurisdição do órgão.

Em relação à reforma do Conselho, os países permanentes têm sido resistentes a 
uma transformação mais profunda do órgão. 0 argumento dos permanentes é que aumentando o número de membros, o Conselho poderia se tornar menos eficiente (VARGAS, 2011). Na prática, estes países não querem perder seu status privilegiado dentro de uma das mais importantes divisões das Nações Unidas, um status que permite reforçar sua influência sobre as áreas periféricas e ajuda a distanciar as semiperiferias dos lugares tradicionalmente ocupados pelo centro no sistema.

Um dos principais argumentos dos países que defendem a reforma é que um órgão que se estruturou no fim de Segunda Guerra Mundial e ainda preserva um arcabouço estrutural que reflete o equilíbrio de poder daquela época é anacrônico diante das mudanças pelas quais o sistema mundial passou desde então, e principalmente, abre um grande debate sobre representatividade, uma vez que houve um aumento de membros das Nações Unidas desde 1945 (AMORIM, 1996). O discurso dos países interessados na reforma reforça que a entrada de novos membros no Conselho de Segurança teria como consequência maior representatividade e legitimidade para as decisões tomadas pelo órgão, e também traria novos valores para o mesmo, o que influenciaria a sua agenda e a sua forma de atuação (VARGAS, 2011).

Além disso, uma das consequências das disparidades dentro do Conselho é o fato de que o órgão não tem espaço para a exposição do parecer de diversos Estados que colaboram ativamente com as missões de paz. Os países periféricos e semiperiféricos que são cooperadores das operações não têm considerável influência nas decisões sobre as quais atuarão. A África é o maior exemplo, já que apesar de ser tema constante das questões que chegam até o órgão, o continente não tem representação fixa, logo, nenhum país africano tem voz permanente para opinar sobre temas que influirão diretamente na vida das pessoas que vivem na África. Quando algum país tem a chance de fazê-lo, é exercendo o papel de membro não permanente.

Weiss (2003) afirma que a questão do veto é um dos maiores obstáculos para a reforma no Conselho. A controvérsia está diretamente ligada aos interesses dos permanentes, empenhados em preservar o seu poder dentro da organização, tirando vantagem do fato de que na Carta das Nações não existe um artigo que prevê a obrigação da renúncia deste direito. 0 problema levanta questões sobre a probabilidade de os permanentes estarem dispostos a partilhar um privilégio tão exclusivo com uma quantidade maior de países, especialmente países semiperiféricos e da periferia. 
Através de negociações, alguns dos países que pleiteiam pela reforma e por assentos permanentes renunciaram ao direito do veto, pelo menos inicialmente, concordando que o debate sobre o privilégio para os novos membros permanentes deveria ser retomado 15 anos após a escolha dos mesmos. Por um lado, a flexibilidade destes países pode resultar em ações mais concretas para a questão da reforma, por outro, ceder em relação a esse aspecto também reflete o caráter dominante dos países do centro nas relações de poder que existem dentro do Conselho e do sistema internacional. 0 recuo de países como Brasil e Índia em relação ao veto é um sinal de que as potências emergentes desejam se inserir num sistema excludente, e não reformar suas estruturas, além de ser também uma forma do centro aparar as pontas da reforma.

Para além dessa questão, existe o fato de que mesmo sob um quadro de crise a reforma não foi apressada. Uma das mais recentes aconteceu em 2003, com a invasão do Iraque pelos EUA. Mesmo acarretando problemas políticos, porque aconteceu sem a adesão do Conselho, a intervenção americana no Iraque expôs como os EUA ignoram critérios que defenderam durante a formação das Nações Unidas, em nome dos interesses individuais. E nada impossibilita que o excesso aconteça outras vezes. Na época, mesmo com a suposta crise de legitimidade que expôs a fragilidade operacional do Conselho, a reforma não aconteceu.

O problema, portanto, não é o consenso sobre a necessidade de se fazer uma reforma, a maioria dos membros da ONU acredita que chegou a hora de preparar a organização para os desafios do novo ordenamento internacional. A questão é o modo como essa reforma deve acontecer, e quais seriam os países favorecidos por tais transformações, um impasse que dificulta um progresso mais significativo em relação à questão. As divergências sobre as formas de reformar atrapalham o decurso das propostas, e preocupações com circunstâncias procedimentais adiam mudanças estruturais que não poderiam ser deixadas de lado.

Em relação à reforma geral, é muito difícil se chegar a um consenso por causa do número elevado de Estados discutindo as propostas, e no caso do Conselho, existe também o esforço para se achar um equilíbrio entre representatividade e eficiência. Mesmo que se chegue a um acordo sobre a representação permanente de regiões como África e América Latina, determinar um candidato final para representar cada localidade é uma tarefa árdua, em que tensões regionais precisarão ser trabalhadas e animosidades históricas 
atenuadas.

\section{Considerações finais}

A despeito da tendência à multipolaridade no sistema internacional, e de muitos afirmarem que é inevitável que a reforma geral da ONU aconteça, o atual clima ainda pende mais para as vontades das grandes potências, que não têm interesse em apressar a reforma da organização e principalmente a do Conselho de Segurança, porque esta beneficiaria diretamente países que não são totalmente convergentes ao seu típico modo de operação. A questão é que, para que uma revisão institucional aconteça na ONU e no Conselho, é preciso vontade política.

Por fim, uma reforma que preze pelas relações horizontais entre os membros da Organização das Nações Unidas, e que seja de fato democrática, não pode se resumir a uma inclusão de novos países às antigas estruturas excludentes, mas sim ter um caráter que, na prática, dilua tais assimetrias e inclua todas as nações que hoje fazem parte da mais plural instituição internacional.

\section{REFERÊNCIAS}

AMORIM, Celso. A Reforma da ONU. Instituto de Estudos Avançados da Universidade de São Paulo, 1996.

. Entre o Desequilíbrio Unipolar e a Multipolaridade: O Conselho de Segurança da ONU no Período Pós-Guerra Fria. In: DUPAS, Gilberto e VIGEVANI, Tullo. $O$ Brasil e as Novas Dimensões da Segurança Internacional. 1ª edição. São Paulo, Editora AlfaÔmega, 1999.

CARTA DAS NAÇÕES UNIDAS. Disponível em <http://www.planalto.gov.br/ccivil 03/decreto/1930-1949/d19841.htm>. Acesso em setembro de 2015.

HERZ, Mônica. A Internacionalização da Política: A Perspectiva Cosmopolita em Face do 
Debate Sobre a Democratização da ONU. Contexto Internacional, v.21, n.2, p.259-289, 1999.

. O Brasil e a Reforma da ONU. Lua Nova, v. 46, p. 77-98, 1999(a).

MILANI et al Atlas da Política Externa Brasileira. Rio de Janeiro, EDUerj, 2014.

MRE. Reformando o Conselho de Segurança das Nações Unidas. Disponível em <http://csnu.itamaraty.gov.br/> Acesso em setembro de 2015.

ONU. Disponível em <http://www.onu.org.br/> Acesso em setembro de 2015.

. Ranking of Military and Police Contributions to UN Operations, Jul-2015. Disponível em <http://www.un.org/en/peacekeeping/contributors/2015/jul15_2.pdf>. Acesso em setembro de 2015.

. Resolution Adopted By The General Assembly 47/62: Question Of Equitable Representation On And Increase In The Membership Of The Security Council. Disponível em:

<http://www.un.org/en/ga/search/view_doc.asp?symbol=A/RES/47/62\&Lang=E\&Area $=$ RESOLUTION $>$ Acesso em setembro de 2015.

. Effective rates of assessment for peacekeeping, 1 January 2013 to 31 December 2015 , based on the scale of assessments adopted by the General Assembly in its resolution $67 / 238$ and the composition of levels endorsed by the Assembly in its resolution 67/239. Disponível em <http://www.un.org/en/ga/search/view doc.asp?symbol=A/67/224/Add.1>. Acesso em setembro de 2015.

SCHOEMAN, Maxi. As Potências em Ascensão e as Operações de Paz. In: Potências Emergentes e Desafios Globais. Cadernos Adenauer XIII (2012), no 2. Rio de Janeiro: Fundação Konrad Adenauer, 2012.

VARGAS, João Augusto Costa. Campanha Permanente: o Brasil e a Reforma do Conselho de Segurança da ONU. Rio de Janeiro: Editora FGV, 2011.

WEISS, Thomas G. The Illusion Of UN Security Council Reform. Washington Quaterly, v.26, p. 147-161, 2003. 